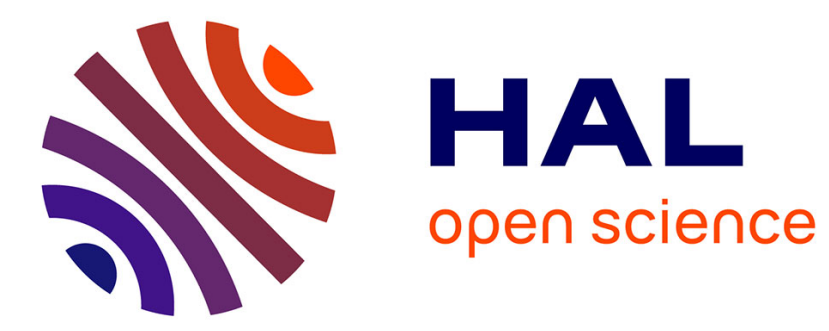

\title{
The influence of ash content on thermophysical properties of ethylene glycol based graphite/diamonds mixture nanofluids
}

Gawel Zyla, Jacek Fal, Patrice Estellé

\section{- To cite this version:}

Gawel Zyla, Jacek Fal, Patrice Estellé. The influence of ash content on thermophysical properties of ethylene glycol based graphite/diamonds mixture nanofluids. Diamond and Related Materials, 2017, 74, pp.81-89. 10.1016/j.diamond.2017.02.008 . hal-01480344

HAL Id: hal-01480344

https://hal-univ-rennes1.archives-ouvertes.fr/hal-01480344

Submitted on 4 Jul 2017

HAL is a multi-disciplinary open access archive for the deposit and dissemination of scientific research documents, whether they are published or not. The documents may come from teaching and research institutions in France or abroad, or from public or private research centers.
L'archive ouverte pluridisciplinaire HAL, est destinée au dépôt et à la diffusion de documents scientifiques de niveau recherche, publiés ou non, émanant des établissements d'enseignement et de recherche français ou étrangers, des laboratoires publics ou privés. 


\title{
The influence of ash content on thermophysical properties of ethylene glycol based graphite/diamonds mixture nanofluids
}

\author{
Gaweł Żyła ${ }^{\mathrm{a}, *}$, Jacek Fal ${ }^{\mathrm{a}}$, Patrice Estellé ${ }^{\mathrm{b}}$ \\ a Department of Physics and Medical Engineering, Rzeszow University of Technology, Rzeszow, Poland \\ ${ }^{b}$ Materials and Thermo-Rheology team at LGCGM, Universite Rennes 1, Rennes, France
}

\begin{abstract}
Since the second half of the twentieth century, nanofluids are very promising engineering materials that can find numerous applications in the processes of heat exchange. Scientist and engineers are developing new and more advanced nanosuspensions which may differ from their physical properties, production costs and practical use. The aim of this paper is to study the differences between two nanofluids containing a mixture of graphite and nanodiamonds with various ash content. Here, ethylene glycol was used as a base fluid. Rheological properties, thermal and electrical conductivities at a constant temperature $298.15 \mathrm{~K}$ were investigated for nanoparticle volume content ranging from 0.004 to 0.023 . It was presented that ash content in nanofluids changes significantly rheological properties of nanofluids containing graphite/nanodiamonds mixture nanoparticles. While the variation in ash content does not affect thermal conductivity of nanofluids, a big impact on electrical conductivity is reported.
\end{abstract}

Keywords: nanofluid, rheology, thermal conductivity, electrical conductivity, nanodiamonds, ash content

\section{Introduction}

In an era of ever-increasing demand for energy, scientists and engineers compete in the design of materials with sophisticated properties. One undoubtedly important groups of materials are suspensions of nanoparticles called nanofluids. At the end of the last century, first experimental studies showing that the addition of the nanoparticles to liquid causes an increase in the thermal conductivity of such material has been introduced. Since then many publications on the thermal conductivity of nanofluids has been presented [1, 2, 3, 4, 5, 6]. Increasing the thermal conductivity of the fluid results in the enormity of possible applications of these materials in many fields of industries [7, 8]. Particularly noteworthy are the possibilities of using these materials in the building industry [9], green energy $[10,11,12]$ and the wider automotive industry [13].

Nanofluids apply not only in industry, but also are promising materials in medical drug delivery systems. Especially interesting here are harmless to the organism gold nanoparticles that can be used in a targeted therapy $[14,15,16]$.

\footnotetext{
${ }^{*}$ Corresponding author

Email address: gzyla@prz.edu.pl (Gaweł Żyła)
}

However, the addition of nanoparticles to the liquid does not remain without effect on its mechanical properties. Increasing concentration of nanoparticles leads to an increase in dynamic viscosity of the suspension $[17,18,19,20]$. It must be taken into consideration when designing systems using nanofluids.

One of the most popular groups of nanoparticles used in the research on thermal conductivity of nanofluids are oxides [21, 22, 23, 24, 25, 26]. Note, however, that in addition to oxides widespread is the use of metals [27, 28, 29], nitrides [30,31, 32, 33] and carbon nanotubes $[34,35,36]$. More recently, graphene was also considered due to high intrinsic thermal properties [37, 38, 39, 40, 41]. A relatively new study group of nanofluids are so-called hybrid nanofluids which contain different types of nanoparticles, in suitable ratios $[42,43,44,45,46]$.

Nanodiamonds (ND) based nanofluids are also very interesting and promising. Branson et al. [47] investigated two types of nanofluids containing nanodiamonds in which the liquid base were poly(glycidol) polymer brush:EG and oleic acid:mineral oil. They showed that the thermal conductivity of these systems is growing much more than the prediction of Maxwell model. In addition, they showed that the increase in thermal 


\begin{tabular}{|lll|}
\hline Nomenclature & & \\
$G^{\prime}$ & storage modulus & {$[\mathrm{Pa}]$} \\
$G^{\prime \prime}$ & loss modulus & {$[\mathrm{Pa}]$} \\
$k$ & thermal conductivity & {$\left[\mathrm{W} \mathrm{m}^{-1} \mathrm{~K}^{-1}\right]$} \\
$K$ & Herschel-Bulkley model consistency & {$\left[\mathrm{Pa} \mathrm{s}^{n}\right]$} \\
$n$ & Herschel-Bulkley model flow index behavior & {$[-]$} \\
$\gamma$ & shear rate & {$\left[\mathrm{s}^{-1}\right]$} \\
$\gamma$ & deformation & {$[-]$} \\
$\eta$ & dynamic viscosity & {$[\mathrm{Pa} \mathrm{s}]$} \\
$\rho$ & density & {$\left[\mathrm{kg} \mathrm{m}^{-3}\right]$} \\
$\tau$ & shear stress & {$[\mathrm{Pa}]$} \\
$\tau$ & Herschel-Bulkley model yield stress & {$[\mathrm{Pa}]$} \\
$\sigma$ & electrical conductivity & {$\left[\mu \mathrm{S} \mathrm{cm}^{-1}\right]$} \\
$\varphi$ & fraction & {$[-]$} \\
& & \\
subscripts & & \\
bf & base fluid & \\
$\mathrm{m}$ & mass & \\
$\mathrm{nf}$ & nanofluid & \\
$\mathrm{p}$ & particle & \\
$\mathrm{v}$ & volume & \\
\hline
\end{tabular}

conductivity with the concentration of nanoparticles is linear. Sundar et al. [48] examined thermophysical properties of water based nanofluids containing ND. Once again, thermal conductivity of those materials was much higher than static theoretical models predictions. Yeganeh et al. [49] described the influence of temperature and volume fraction of nanodiamonds on thermal conductivity of deionized water. Yu et al. [50] presented results of experimental studies on thermal conductivity of ethylene glycol based nanofluids containing low volume concentration of diamond nanoparticles. They described that thermal conductivity enhancement is correlated to the $\mathrm{pH}$ values of the nanofluids which is directly linked to the stability of samples. Tyler et al. [51] examined thermophysical properties of nanofluids and polymer-based nanocomposites containing nanodiamonds.

Sundar et al. [52] carried out investigation on enhancement in electrical conductivity for nanodiamondnickel (ND-Ni) nanocomposite dispersed in water (W) and ethylene glycol (EG). They conducted study for three different volume concentrations $(0.02 \%, 0.05 \%$, $0.1 \%$ ) of nanocomposite at temperatures between $24^{\circ} \mathrm{C}$ and $65^{\circ} \mathrm{C}$ for two different base fluids, water and ethylene glycol, respectively. The experimental data clearly indicate that water-based nanofluids have much higher electrical conductivity enhancement than those based on ethylene glycol. Additionally, they observed the increase in electrical conductivity with increase in ND$\mathrm{Ni}$ nanocomposite load in base fluid for both water and ethylene glycol. They recorded enhancement in electrical conductivity for $0.1 \mathrm{vol}$. \% water based nanofluid at level $1339.81 \%$ and $853.25 \%$ at $24^{\circ} \mathrm{C}$ and $65^{\circ} \mathrm{C}$, respectively compared to the pure water. While ND-Ni ethylene glycol based nanofluids shows enhancement in electrical conductivity at level $199.52 \%$ and $200.23 \%$ at the same condition as water based nanofluids. Shukla and Aiyer [53] studied electrical properties of transformer oil with nanodiamonds inclusion. They found that addition of nanodiamonds particles up to $5 \mathrm{wt}$. \% into transformer oil not cause changes in electrical resistivity and dissipation factor.

Fontes et al. [54] compared basic thermophysical properties of nanofluids containing carbon nanotubes and nanodiamonds. They found that thermal conductivity enhancement is higher in ND nanofluids. In addition, a drastic degradation of the dielectric strength by the diamond nanoparticles was reported. Wilson et al. [55] studied thermophysical properties of nanofluids containing nanodiamond for it use in an oscillating heat pipe. Liu et al. [56] investigated the influence of nanodiamonds addition in engine oil. They concluded that adding nanodiamond particles to engine oil results in increasing the maximum engine power and the max- 
imum torque while the fuel consumption is decreased. Oil based nanofluids contained nanodiamonds were investigated also by Taha et al. [57]. They measured viscosity and thermal conductivity of various concentrations of nanodiamonds in dielectric insulator mineral oil and reported that this material exhibin Newtonian nature with viscosity enhancement well predicted by Einstein model. Nanofluids containing various types of nanodiamonds are an area of interest of many scientists all over the World [58, 59, 60, 61, 62, 63, 64].

As a new trend in the growing field of nanodiamonds based nanofluids, the aim of this paper is to report and discuss the thermophysical properties of ethylene glycol based nanofluids containing graphite/diamonds mixture with various ash content. So, experimental measurements for rheological properties, thermal and electrical conductivities were performed considering the influence of nanoparticles loading and ash content.

\section{Materials and methods}

\subsection{Nanoparticles characterization}

Nanopowders presently used to produce nanofluids were purchased from the Plasmachem $\mathrm{GmbH}$ (Berlin, Germany). Two types of nanopowders with various ash content were used. First type of nanoparticles (NP1) was raw material in which ash content was over $5 \mathrm{wt} . \%$, while in second type (NP2) ash content did not exceed 0.3 wt.\%. The average diamond primary particle size in both samples was $4 \mathrm{~nm}$ as indicated by manufacturer. Density of powders was measured by means of helium pycnometer Ultrapyc 1200e (Quantachrome Instruments, Boynton Beach, USA). Temperature of measuring chamber was stabilized at $298 \mathrm{~K}$ using thermostat Grant TC120 (Grant Instruments, Cambridgeshire, GB). Basic nanoparticle properties given by the manufacturer were summarized in Table 1 . This Table shows in particular that the decrease in ash content induces an increase in specific surface.

The nanopowder NP1 and NP2 were characterized by scanning electron microscopy (SEM) and X-ray diffraction (XRD) for size, structural and chemical evaluation. SEM was performed with JEOL-JSM-6301F (JEOL USA Inc., Peabody, USA) equipment coupled with energy dissipative X-ray spectrometer (EDS) that was used for chemical characterization of nanopowders. Samples were prepared from the deposition of nanoparticles on a carbon substrate.

Powder XRD experiments were performed on a Bruker D8 Advance (Bruker GmbH, Karlsruhe, Germany) diffractometer working in a $\theta-2 \theta$ modified
Table 1: Basic properties of used graphite/diamonds nano-mixture.

\begin{tabular}{|c|c|}
\hline \multicolumn{2}{|r|}{ NP1 } \\
\hline Appearance & black powder \\
\hline CAS-No. & $7782-40-3$ \\
\hline Lot number & PL-GD-15051 \\
\hline Ash content & 5,9 wt. $\%$ at $1000^{\circ} \mathrm{C} 6 \mathrm{~h}$ \\
\hline BET surface & $368 \mathrm{~m}^{2} \mathrm{~g}^{-1}$ by $\mathrm{N}_{2}$ adsorption \\
\hline Density & $2540.4 \mathrm{~kg} \mathrm{~m}^{-3}$ \\
\hline Diamond phase & $26 \%$ by oxidation of $\mathrm{sp}^{2}$ phase \\
\hline \multicolumn{2}{|r|}{ NP2 } \\
\hline Appearance & black powder \\
\hline CAS-No. & $7782-40-3$ \\
\hline Lot number & PL-GD-MOF-YF-1601 \\
\hline Ash content & 0.29 wt. $\%$ at $1000^{\circ} \mathrm{C} 6 \mathrm{~h}$ \\
\hline BET surface & $470 \mathrm{~m}^{2} \mathrm{~g}^{-1}$ by $\mathrm{N}_{2}$ adsorption \\
\hline Density & $2521.4 \mathrm{~kg} \mathrm{~m}^{-3}$ \\
\hline Diamond phase & $26 \%$ by oxidation of $s^{2}$ phase \\
\hline
\end{tabular}

Bragg-Brentano geometry and equipped with a LynxEye fast detector. The $\mathrm{Cu} \mathrm{K} \alpha 1$ radiation $(\alpha=1.5406 \AA)$ is selected using a $\mathrm{Ge}(111)$ monochromator. The $2 \theta$ angular domain was scanned with a step size of $0.03^{\circ}$ and integration time of $1970 \mathrm{~s}$ per step. A misoriented single crystalline Si sample holder was used to avoid any background signal from it. SEM images for both types of nanopowder are shown in Fig. 1 at accelerating voltage of $5 \mathrm{kV}$ and magnification of 10000. SEM images indicate that the two samples have different structure and morphology. NP2 appear mainly in the form of aggregates composed of fine particles while in NP1, one can see the presence of larger particles with irregular shapes.

EDS images and composition from EDS spectroscopy of both nanopowders are displayed in Fig. 2. A comparison of figures 2A) and 2C) shows the presence of spherical particles in NP1. The chemical composition of NP1 nanopowder from the EDS spectroscopy and corresponding to the spectrum 6 displayed in Fig. 2A) is reported in Fig. 2B). It evidences that identified spherical particles mainly contain Fe. It should be mentioned that similar chemical composition and identical constituents were obtained considering all spectra associated to spherical particles reported in Fig. 2A). Fig. 2B) also shows that main component of NP1 sample is C as expected, in agreement with manufacturer specifications related to graphite and diamond mixtures. It should be noted that $C$ cannot be solely attributed to carbon substrate supporting the samples due to large magnitude of peak. An insight in Fig. 2D) shows that Fe is absent in NP2 sample indicating that this chemical component seems to be related to the ash content. Here 


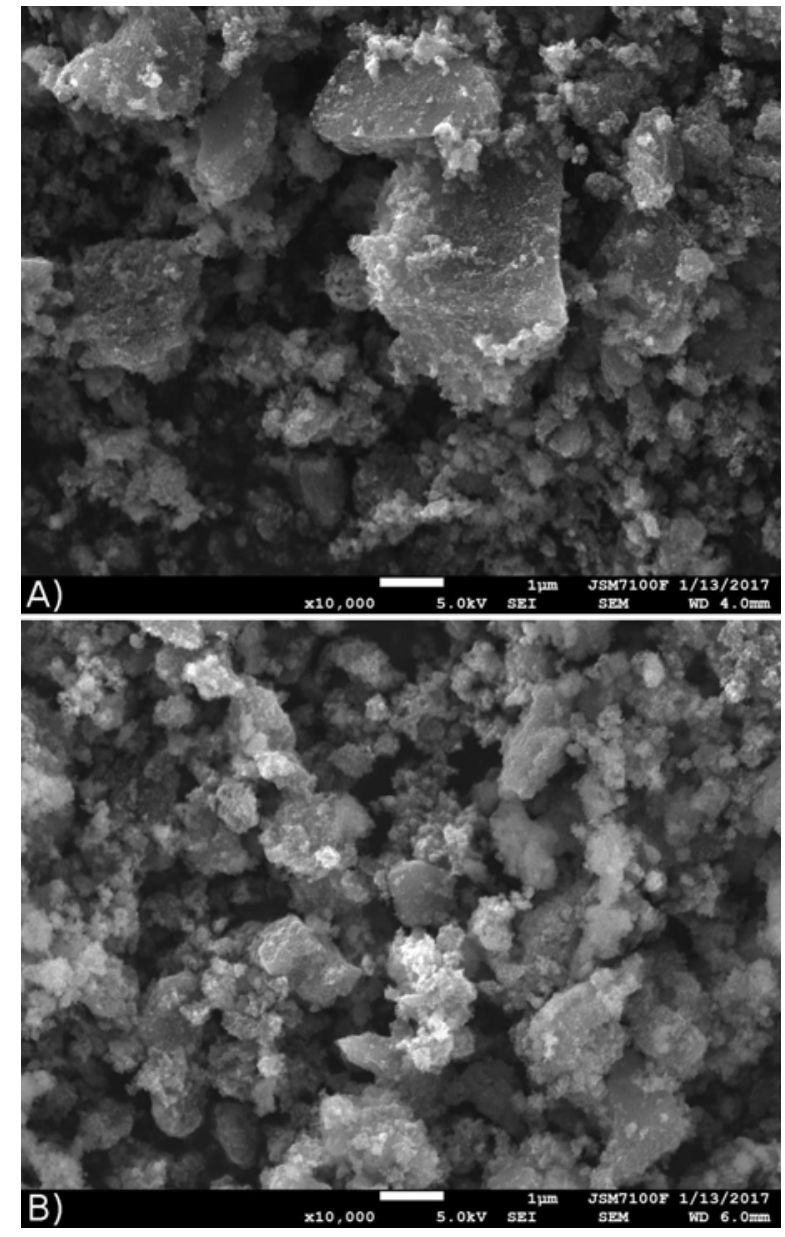

Figure 1: SEM images of nanopowders A) NP1 and B) NP2

again EDS spectra shows that main chemical component is $\mathrm{C}$ for nanopowder NP2. Other components are not considered due to irrelevant amount.

In both diffractograms, the most pronounced feature at $25.9^{\circ}$ in the Fig. 3 is attributed to the (002) of graphite. The peak around $43.7^{\circ}$ belongs to different compounds including diamond (111) and graphite (100) appearing as a shoulder around $45^{\circ}$. It is also noted that all apparent peaks are quite broad indicating the poorly crystalized structure of both nanopowders in agreement with the small sizes of ordered domains of both graphite and diamond phases (evaluated with Topas software) of around $2 \mathrm{~nm}$ and $5 \mathrm{~nm}$, respectively. Other peaks at $62.5^{\circ}$ and $78^{\circ}$ are too large to be unambiguously assigned and certainly correspond to ash. Main difference between nanopowders is shown at $30^{\circ}$ and $40^{\circ}$ corresponding to ash with lower content for NP2. In addition, small peaks in the diffractogram of NP1 at both $30.1^{\circ}$ and $35.5^{\circ}$ are in agreement with maghemite $\mathrm{Fe}_{2} \mathrm{O}_{3}$ in agreement with EDS characterization reported above and indicating the presence of Fe. X-ray diffraction studies confirm that the nanopowders contain graphite and diamond phases as specified by the manufacturer. XRD analysis performed with Topas software allowed to evaluate the proportion of both graphite and diamond for both samples with similar values of around $25 \%$ and $75 \%$, respectively.

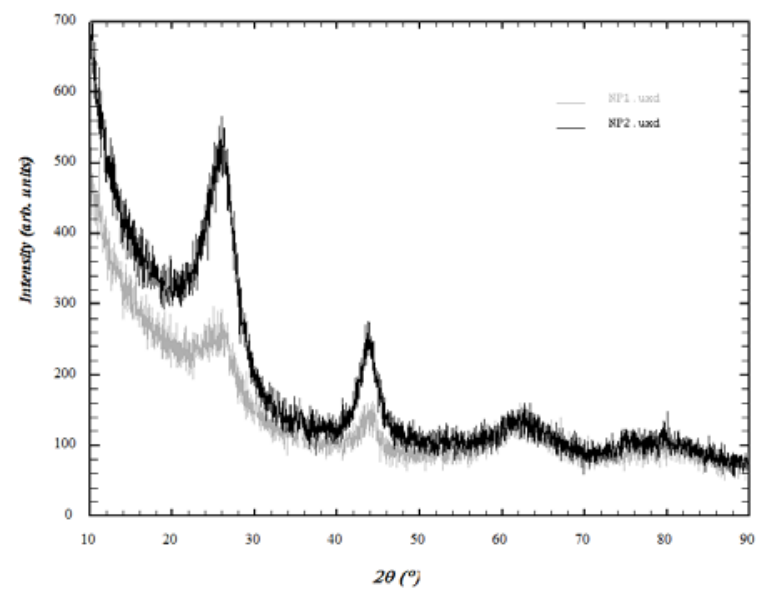

Figure 3: X-ray diffractogram for the nanopowders.

\subsection{Sample preparation}

Nanofluids containing two types of nanoparticles (labeled S1, S2 for NP1 and NP2 nanoparticles respectively) were prepared by mechanical dispersing nanoparticles in base fluid. Pure ethylene glycol (POCH, Avantor Performance Materials Poland, Gliwice, Poland) was used as base fluid and no surfactant was added (with density $1113.7 \mathrm{~kg} \mathrm{~m}^{-3}$ at 293.15 K [65]). An analytical balance WAS 220/X (Radwag, Radom, Poland) with the accuracy of $0.1 \mathrm{mg}$ was used to accurately weight mass of nanoparticles and ethylene glycol. For breaking possible agglomerates, a Genius 3 Vortex (IKA, Staufen, Germany) was used for $30 \mathrm{~min}$, and then ultrasound action for $200 \mathrm{~min}$ in ultrasoundwave bath Emmi 60 HC (EMAG, MoerfeldenWalldorf, Germany) was conducted. Fig. 4 presents pictures of prepared samples immediately after preparation and few days later up to one week. It might be noticed that sedimentation of nanoparticles occurs within the samples. First the samples appear visually stable during few hours for both nanofluids S1 and S2. After one day at rest, sedimentation starts to produce even for low concentration. A comparison between pictures for nanofluids S1 and S2 shows that ash content penalizes the stability of the suspensions and increase the rate 

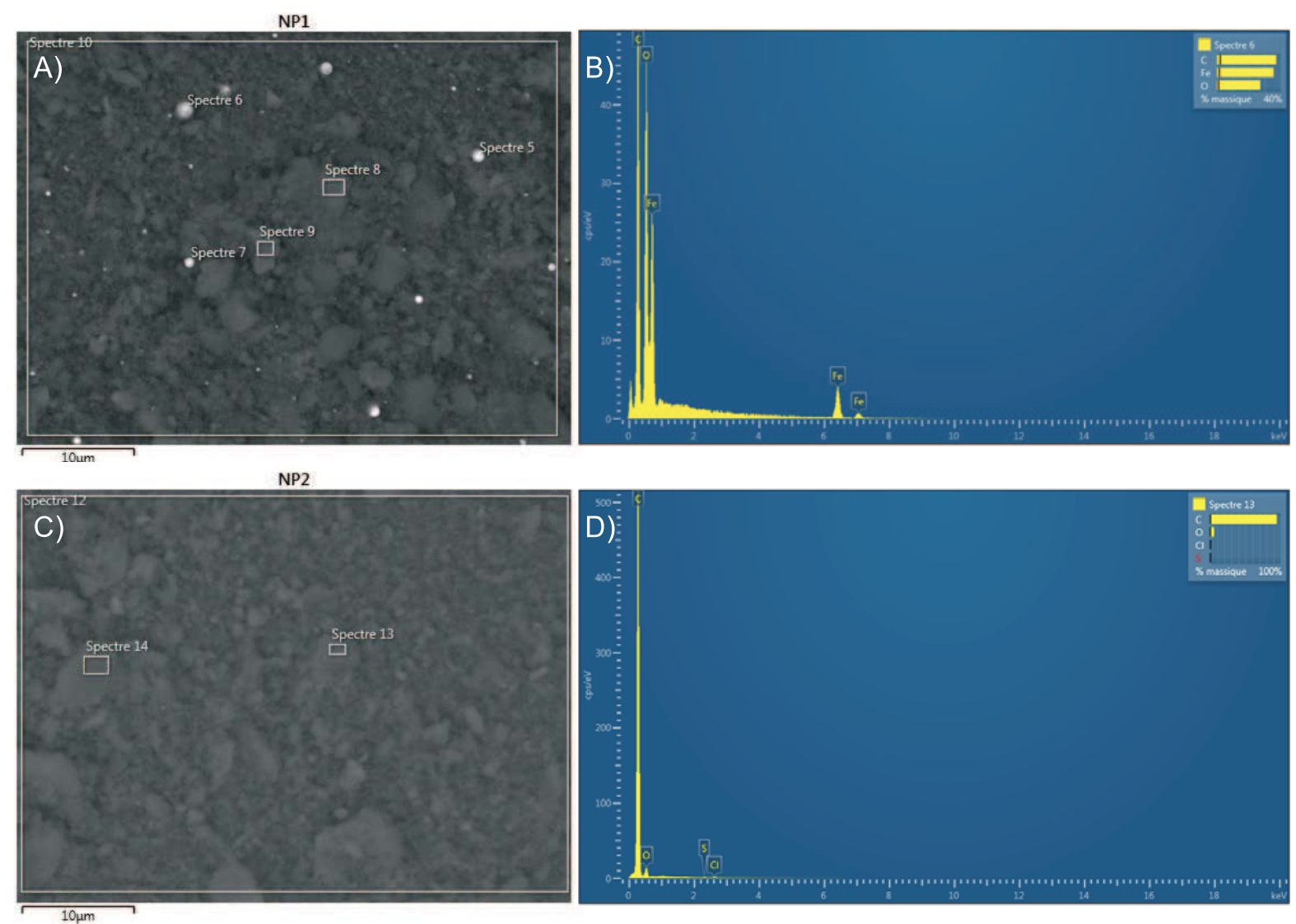

Figure 2: EDS images and analysis: A) EDS image of NP1, B) spectra analysis of NP1, C) EDS image of NP2, D) spectra analysis of NP2.

of sedimentation as sedimentation produces earlier with S1. Consequently, all measurements reported thereafter in the paper were performed immediately after sample preparation.

The samples were prepared in mass concentrations from $1 \%$ to $5 \%$, and the mass concentrations were recalculated to the volumetric fractions by using the equation:

$$
\varphi_{V}=\frac{\varphi_{m}}{\rho_{p}\left(\frac{\varphi_{m}}{\rho_{p}}+\frac{1-\varphi_{m}}{\rho_{b f}}\right)} .
$$

\subsection{Measuring system}

A HAAKE MARS 2 rheometer (Thermo Electron Corporation, Karlsruhe, Germany) with Peltier system coupled with a Phoenix 2 thermostat (Thermo Electron Corporation, Karlsruhe, Germany) was used for shear flow and viscoelastic structure measurements of nanofluids. A cone-plate measuring geometry with cone angle of $2^{\circ}$ and $60 \mathrm{~mm}$ diameter was used. The volume of sample was $2 \mathrm{~cm}^{3}$, and it was measured with HTL
Labmate Pro LMP5000 single channel pipette (HTL Lab Solutions, Warsaw, Poland), with accuracy of $0.1 \%$. Storage $\left(G^{\prime}\right)$ and loss $\left(G^{\prime \prime}\right)$ modulus, related to viscoelastic behavior of nanofluids, were determined in oscillatory experiments where deformation was changed from 0.1 to 10 , frequency $1 \mathrm{~Hz}$ and temperature of $298.15 \mathrm{~K}$. Shear flow behavior of nanofluids at same constant temperature of $298.15 \mathrm{~K}$ was measured in shear rate range from 0.1 to $1000 \mathrm{~s}^{-1}$, shear rate steps were planed on logarithmic scale. Each sample was stay at rest between the cone and plate geometry during 5 minutes under a constant temperature of $298.15 \mathrm{~K}$ before measurement. In addition, to minimize the impact of the environment on rheological measurements, a Teflon solvent trap was used to isolate the measuring system from the ambient.

Thermal conductivity measurements were performed with a KD2 Pro Thermal Properties Analyzer (Decagon Devices Inc., Pullman, Washington, USA). In this equipment, thermal conductivity of liquid samples is measured from the transient line heat source method. 


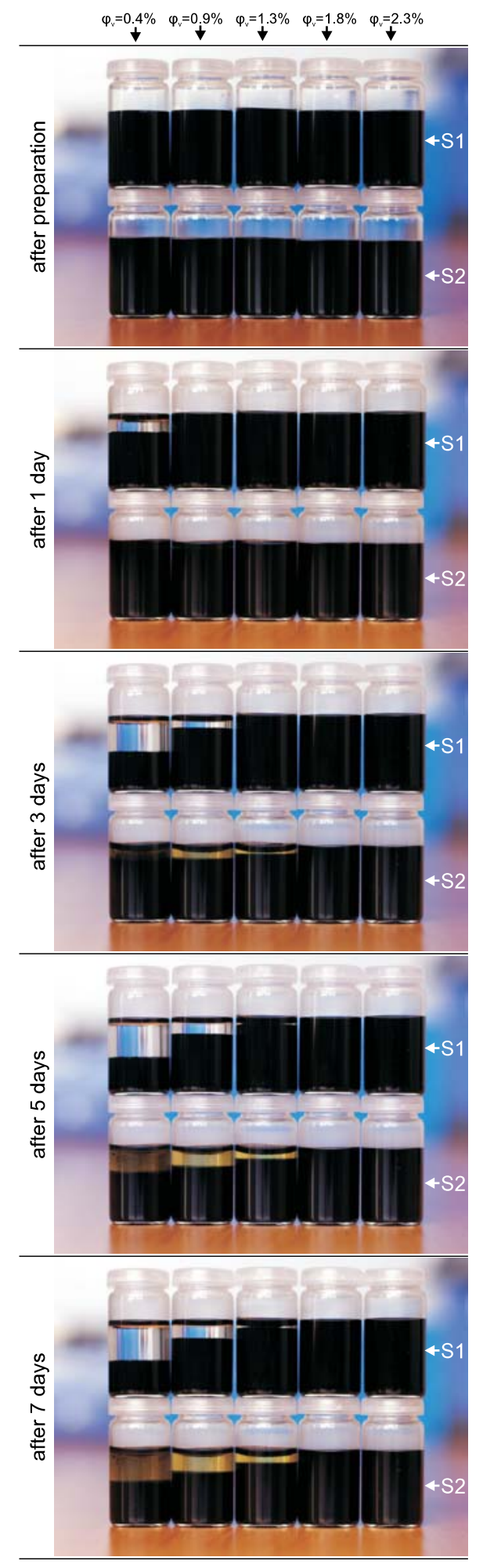

Figure 4: Pictures of S1 and S2 nanofluids with various volume concentrations of nanoparticles.
Standard uncertainty of measurement was estimated at $2 \%$, as presented in recent work [66]. Thermal conductivity of materials was also measured at constant temperature of $298.15 \mathrm{~K}$ for various volume fractions of nanoparticles. The vial with the sample and the probe was placed in water bath MLL 547 (AJL Electronic, Cracow, Poland) for stabilization of temperature. As recommended by the manufacturer, 15 minutes of interval was considered between successive measurements. As a result, the measurement reported here are the average of four measurements taken with this interval.

Finally, electrical conductivity of the two types of nanofluids containing diamonds nanoparticles was also measured using conductivity meter MultiLine 3410 (WTW GmBH, Weilheim, Germany) with TetraCon 925 with four electrodes. Conductivity cell (TetraCone 925) has also inbuilt temperature sensor, which allows to simultaneously measure electrical conductivity and temperature of the sample. Conductivity meter with TetraCon 925 before measurements was calibrated using standard conductivity solution HI 7031, LOT: 7695 (Hanna Instruments, Woonsocket, USA) at $298.15 \mathrm{~K}$, and the standard deviation of measurements was $0.1 \%$. The full procedure of calibration was presented in Ref. [32]. The temperature was stabilized using water bath for at least 30 minutes before measurements started. Measurements were carried out every 15 minutes for three hours after the temperature was stabilized. During this period, as shown in Fig. 4, all the samples keep visually stable. The values of electrical conductivity were calculated as an average of these measurements.

\section{Results and discussion}

\subsection{Rheological properties}

Oscillatory experiments at $298.15 \mathrm{~K}$ are reported in Fig. 5 considering the evolution of storage $\mathrm{G}^{\prime}$ and loss $G$ " moduli with deformation for both nanofluids and entire range of nanoparticle volume content. First, a quite linear regime with hallmarked plateau is observed for both G' and G" at low deformation up to a critical value of deformation around 0.006 for all nanofluids, except for S2 at 0.004 volume fraction of nanoparticles. Such a plateau is generally defined as the linear viscoelastic domain. Beyond this domain, the nanofluids start to flow. One can also observed that G' is always higher than G". So, this result evidence the viscoelastic structure of investigated nanofluids at low strain rate. This trend is dependent to nanoparticle volume content as G' and G" increase with concentration for both nanofluids. After 
the plateau, G' and G" decrease when the deformation is increased indicating the breakdown of viscoelastic structure of nanofluids and their flowing. In addition, it should also be reported a small overshoot for G" for higher nanopowder content and strain rate around 0.5 before its decrease when the strain rate is increased. An insight in the values of G' and G" shows that the moduli are higher with $S 2$ than $S 1$ at similar volume content. These results show that ash content increase reduces the build-up of nanoparticle structural network within the base fluid. This agrees with stability results previously discussed.
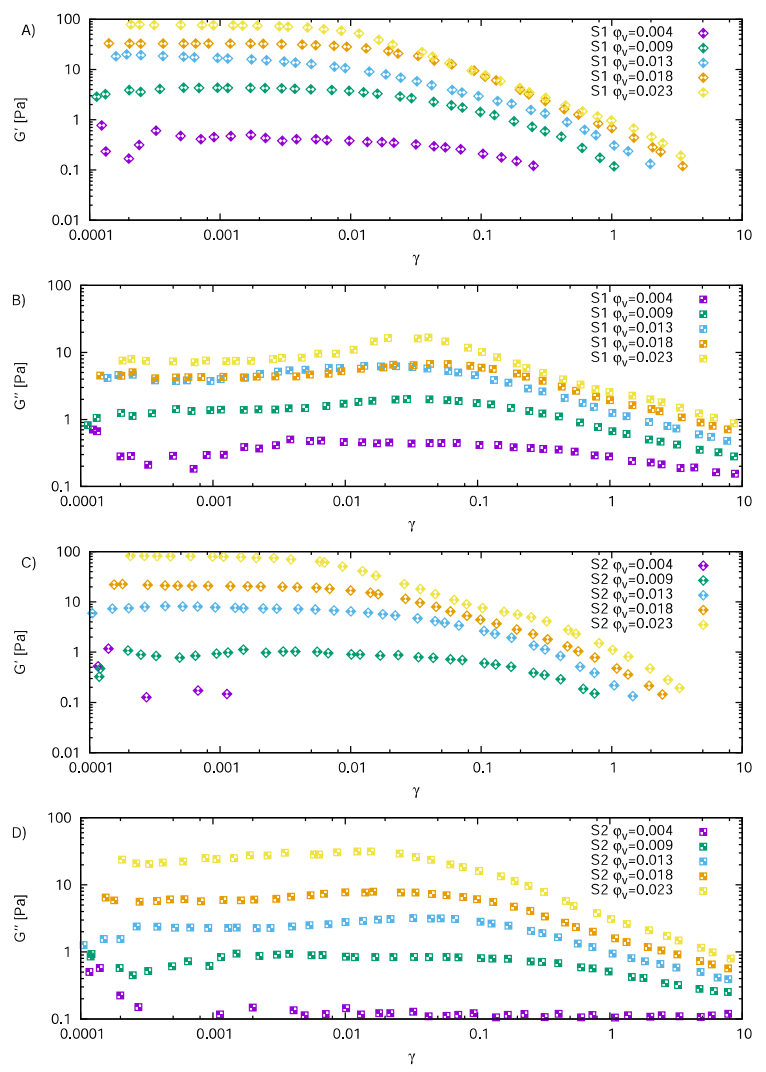

Figure 5: Storage $\left(G^{\prime}\right)$ and loss $\left(G^{\prime \prime}\right)$ moduli as a function of deformation for various volume fractions of nanoparticles in nanofluids at a constant temperature $298.15 \mathrm{~K}$ and a oscillation frequency of $1 \mathrm{~Hz}$ for A), B) S1 and C), D) S2 samples.

Shear flow behavior of nanofluids is shown in Fig. 6 A) and B), where shear stress is plotted versus the shear rate. First, it is observed that nanofluid S2 at $1 \mathrm{wt}$. \% behave in Newtonian manner with similar viscosity value than the one of base fluid. So, this explains the evolution of $G^{\prime}$ and $G$ " for this nanofluid reported above.

For all other nanofluids, the figure shows that shear stress sharply increases with shear rate up to a critical shear rate lower than $0.4 \mathrm{~s}^{-1}$. This is related to the predominance of viscoelastic structure of nanofluids in this shear rate range. After this critical shear rate, when viscoelastic structure is breakdown, nanofluids start to flow and behave in a non-Newtonian shear-thinning manner with the existence of a yield stress value.

Such a behavior in the flowing regime can be well modeled by the Herschel-Bulkley (H-B) model defined by equation (2).

$$
\tau=\tau_{0}+K \dot{\gamma}^{n}
$$

Fit of Herschel-Bulkley model was performed in shear rate range $0.4-1000 \mathrm{~s}^{-1}$ with Origin Pro 9.1 software (OriginLab Corporation, Northampton, USA) and in all cases $R^{2}$ is higher than 0.999 . The parameter values of Herschel-Bulkley model are reported in Table 2 and presented in Fig. 7 for all nanofluids and concentrations. Comparison of $\mathrm{H}-\mathrm{B}$ model with experimental data was presented in Fig. 6, and shows the good agreement between experiments and eq. (2) in the shear rate range $0.4-1000 \mathrm{~s}^{-1}$.
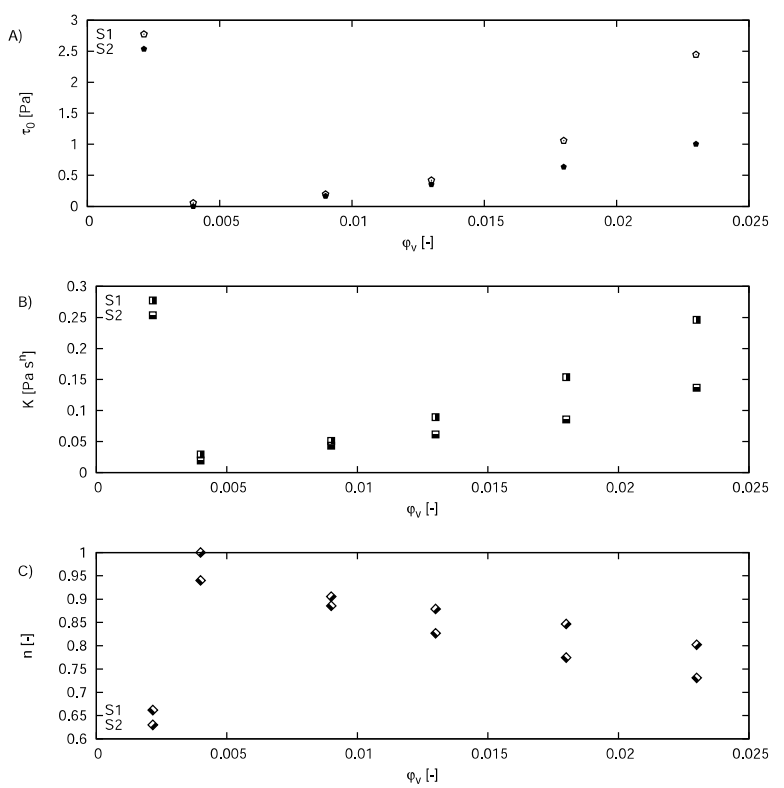

Figure 7: Values of calculated A) yield stress, B) consistency, C) flow index behavior of $\mathrm{S} 1$ and $\mathrm{S} 2$.

The results of fitting, reported in Table 2 and Fig. 7, shows that for both nanofluids, yield stress value increases with nanoparticle volume content and that yield stress of S1 is higher than the one of S2. This is related to the higher content in ash. It is also observed that consistency values increase with volume content, this trend 

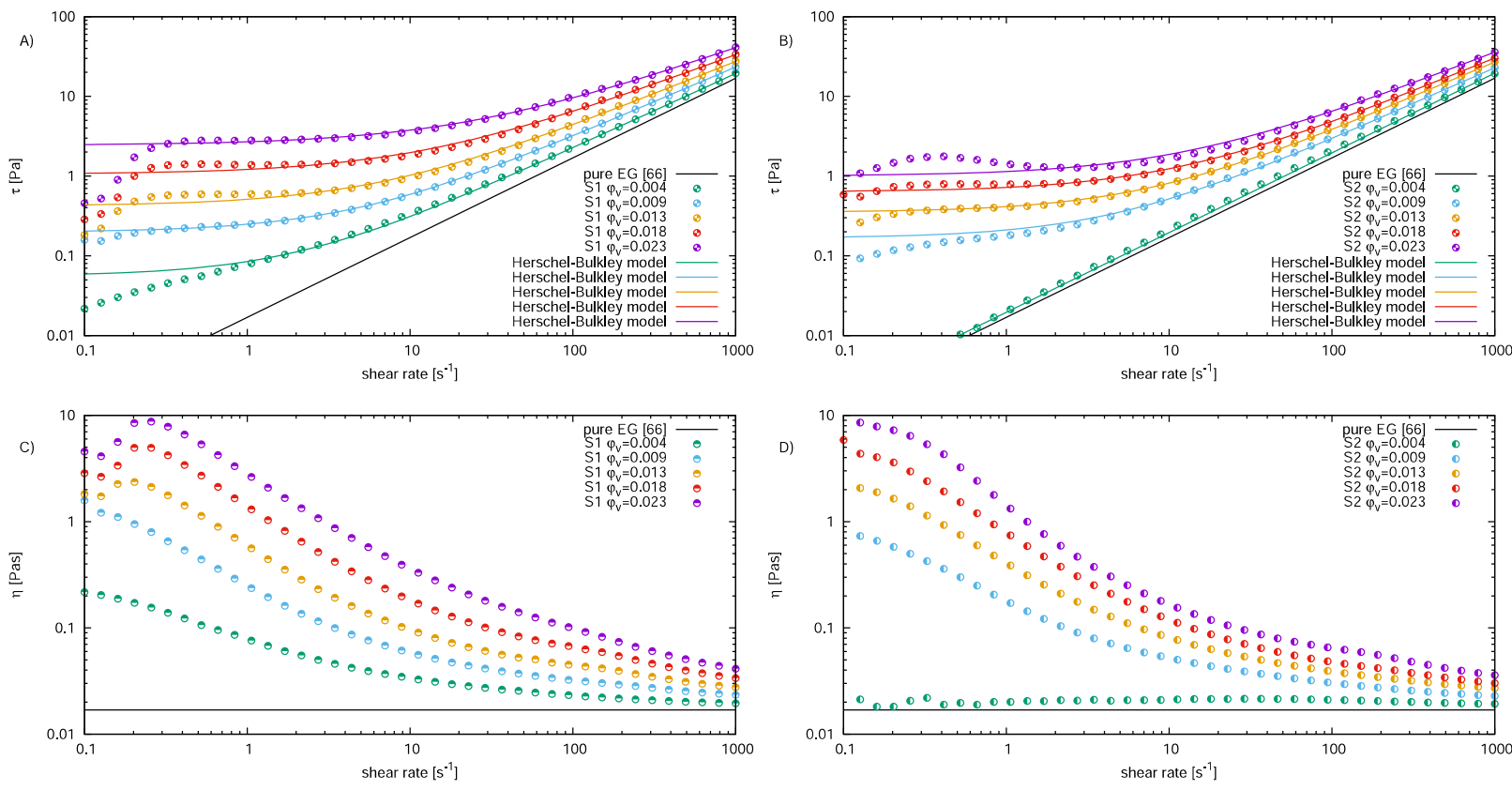

Figure 6: A), B) dependence of shear stress on shear rate (flow curves) for S1 and S2 samples at 298.15 K. C), D) dependence of viscosity on shear rate (viscosity curves) for S1 and S2 samples at $298.15 \mathrm{~K}$.

Table 2: Herschel-Bulkley rheological parameters extracted from flow curves of nanofluids in shear flow regime.

\begin{tabular}{cc|ccc|ccc}
\hline & & \multicolumn{3}{|c}{$\mathrm{S} 1$} & & $\mathrm{~S} 2$ & \\
\hline$\varphi_{m}$ & $\varphi_{V}$ & $\tau_{0}$ & $\mathrm{~K}$ & $\mathrm{n}$ & $\tau_{0}$ & $\mathrm{~K}$ & $\mathrm{n}$ \\
- & - & $\mathrm{Pa}$ & $\mathrm{Pa} \mathrm{s}^{n}$ & - & $\mathrm{Pa}$ & $\mathrm{Pa} \mathrm{s}^{n}$ & - \\
\hline 0.01 & 0.004 & $0.05560 \pm 0.00000$ & $0.02929 \pm 0.00037$ & $0.94010 \pm 0.00195$ & $0.00000 \pm 0.00000$ & $0.01954 \pm 0.00000$ & $1.00000 \pm 0.00000$ \\
0.02 & 0.009 & $0.19726 \pm 0.00849$ & $0.05105 \pm 0.00063$ & $0.88574 \pm 0.00185$ & $0.16695 \pm 0.01199$ & $0.04357 \pm 0.00081$ & $0.90544 \pm 0.00277$ \\
0.03 & 0.013 & $0.42123 \pm 0.02914$ & $0.08943 \pm 0.00291$ & $0.82687 \pm 0.00486$ & $0.35174 \pm 0.00815$ & $0.06150 \pm 0.00063$ & $0.87890 \pm 0.00153$ \\
0.04 & 0.018 & $1.05886 \pm 0.05568$ & $0.15391 \pm 0.00718$ & $0.77460 \pm 0.00696$ & $0.63505 \pm 0.01862$ & $0.08551 \pm 0.00169$ & $0.84678 \pm 0.00296$ \\
0.05 & 0.023 & $2.44504 \pm 0.06063$ & $0.24627 \pm 0.00960$ & $0.73113 \pm 0.00581$ & $1.00363 \pm 0.07311$ & $0.13683 \pm 0.00825$ & $0.80227 \pm 0.00900$ \\
\hline
\end{tabular}

being more important again with S1. Finally, flow index behavior of both nanofluids decrease with volume content. At similar volume content, lower values are obtained also with S1. Fig. 6 presents also viscosity curves of examined materials.

The results reported here imply that apparent viscosity, define as the ratio of shear stress to shear rate and described in Fig. 6, decreases with shear rate when viscoelastic structure is breakdown and yield stress exceeded, and that apparent viscosity at fixed shear rate increases with volume content in nanoparticles as mainly reported with nanofluids.

\subsection{Thermal conductivity}

Results of experimental studies on thermal conductivity were summarized in Table 3 . It also shows the comparison of the thermal conductivity of the suspension to the thermal conductivity of pure ethylene glycol. The results indicate that the thermal conductivity of nanofluids increases linearly with increasing volume fraction of nanoparticles in the sample.

It is also apparent that S1 nanofluids presents a slightly higher thermal conductivity than the S2 samples. However, these differences are vanishingly small, and are smaller than the $2 \%$ measurement uncertainty. This indicates that thermal conductivity enhancement is mainly governed by graphite/diamond phase. Therefore, it is possible to fit a linear function, which could be 
Table 3: Experimental values of the thermal conductivity of S1 and S2 nanofluids for various volume fraction at temperature $T=298.15 \mathrm{~K}$.

\begin{tabular}{cc|cc|cc}
\hline & & \multicolumn{2}{|c}{$\mathrm{S} 1$} & \multicolumn{2}{c}{$\mathrm{S} 2$} \\
\hline$\varphi_{m}$ & $\varphi_{V}$ & $k_{n f}$ & $k_{n f} / k_{b f}$ & $k_{n f}$ & $k_{n f} / k_{b f}$ \\
- & - & $\mathrm{W} \mathrm{m}^{-1} \mathrm{~K}^{-1}$ & - & $\mathrm{W} \mathrm{m}^{-1} \mathrm{~K}^{-1}$ & - \\
\hline 0.00 & 0.000 & 0.2438 & 1.00000 & 0.2438 & 1.00000 \\
0.01 & 0.004 & 0.2455 & 1.00697 & 0.2450 & 1.00492 \\
0.02 & 0.009 & 0.2485 & 1.01928 & 0.2483 & 1.01825 \\
0.03 & 0.013 & 0.2523 & 1.03466 & 0.2515 & 1.03158 \\
0.04 & 0.018 & 0.2545 & 1.04389 & 0.2528 & 1.03671 \\
0.05 & 0.023 & 0.2580 & 1.05824 & 0.2568 & 1.05312 \\
\hline
\end{tabular}

used to describe the dependence of thermal conductivity on volume fraction of nanoparticles in ethylene glycol based graphite/diamonds mixture nanofluids in the examined range of volume fractions. Fitting such a linear function to the experimental data was also performed with OriginPro 9.1 software. The following obtained model for S1:

$$
\frac{k_{n f}}{k_{b f}}=1+2.49 \varphi_{V}
$$

with standard error of parameter 0.07 , and coefficient of determination, $R^{2}$, is 1 , and for $\mathrm{S} 2$ :

$$
\frac{k_{n f}}{k_{b f}}=1+2.21 \varphi_{V}
$$

with standard error of parameter 0.08 , and $R^{2}=0.9999$.

Fig. 8 presents results of experimental studies on thermal conductivity of S1 and S2 samples. It also shows that proposed linear function (3) and (4) modeled experimental data well. Observed enhancement in thermal conductivity is lower than presented by Yu et al. [50] for ethylene glycol based nanofluids containing pure nanodiamonds.

\subsection{Electrical conductivity}

The electrical conductivity of two types of ethylene glycol based nanofluids (S1 and S2) with various volume concentration and different level of purity of nanodiamonds were investigated. The results of these experimental data are listed in Table 4 and plotted in Fig. 9. For both nanofluids S1 and S2, one can observe a nonlinear increase in electrical conductivity with increasing volume concentration of nanoparticles in the base fluid, in agreement with previous studies $[32,52,54]$. For nanofluids S2, we can observe much higher increase in electrical conductivity than for
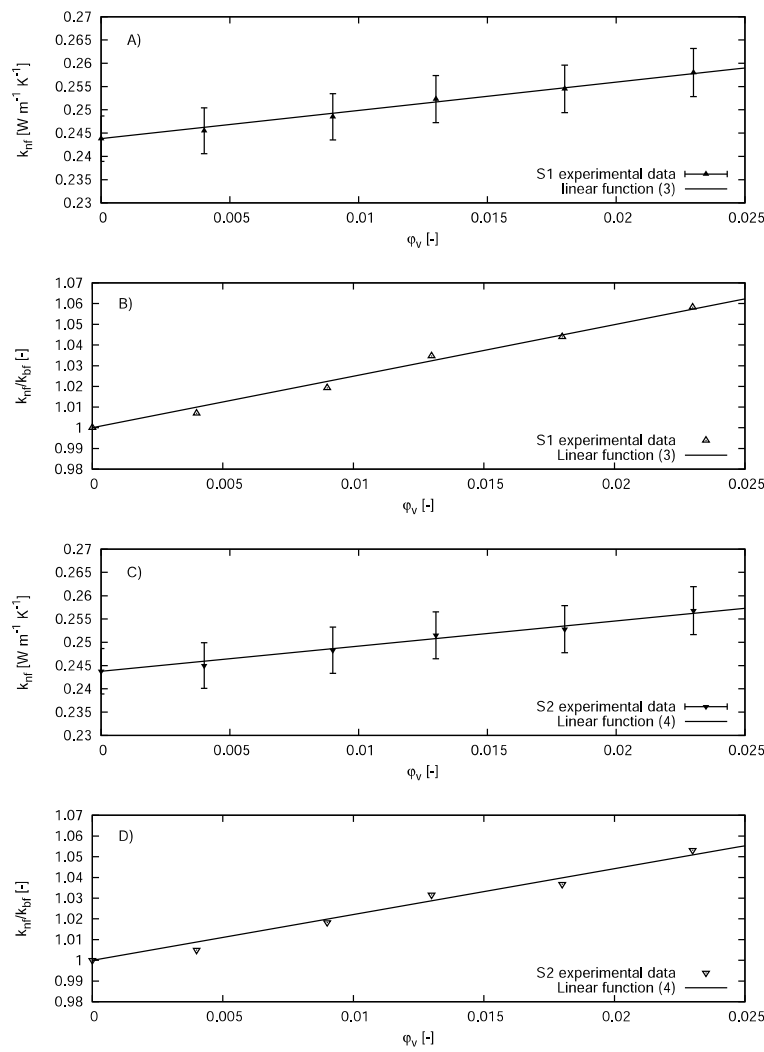

Figure 8: Dependence of thermal conductivity of A) S1 and C) S2, and thermal conductivity enhancement for B) S1 and D) S2 nanofluids on volume fraction of particles at $298.15 \mathrm{~K}$.

Table 4: Experimental values of the electrical conductivity of S1 and S2 nanofluids for various volume fraction at temperature $T=$ $298.15 K$.

\begin{tabular}{cc|cc|cc}
\hline & & \multicolumn{2}{|c}{$\mathrm{S} 1$} & \multicolumn{2}{c}{$\mathrm{S} 2$} \\
\hline$\varphi_{m}$ & $\varphi_{V}$ & $\sigma_{n f}$ & $\sigma_{n f} / \sigma_{b f}$ & $\sigma_{n f}$ & $\sigma_{n f} / \sigma_{b f}$ \\
- & - & $\mu \mathrm{S} \mathrm{cm}^{-1}$ & - & $\mu \mathrm{Sm}^{-1}$ & - \\
\hline 0.00 & 0.000 & 0.90 & 1.00 & 0.90 & 1.00 \\
0.01 & 0.004 & 6.56 & 7.29 & 59.85 & 66.49 \\
0.02 & 0.009 & 9.99 & 11.10 & 90.56 & 100.62 \\
0.03 & 0.013 & 13.21 & 14.68 & 121.20 & 134.67 \\
0.04 & 0.018 & 16.13 & 17.92 & 147.56 & 163.96 \\
0.05 & 0.023 & 18.20 & 20.22 & 171.65 & 190.73 \\
\hline
\end{tabular}

S1 nanofluid, which can explained by higher purity of nanoparticles used to produce S2 samples.

Change of electrical conductivity with increasing of volume fraction of nanoparticles might be described with a good accuracy by a second degree polynomial 
for S1 samples:

$$
\frac{\sigma_{n f}}{\sigma_{b f}}=1+1380.52 \varphi_{V}-24026.23 \varphi_{V}^{2}
$$

with $R^{2}=0.9979$, and for S2:

$$
\frac{\sigma_{n f}}{\sigma_{b f}}=1+13582.97 \varphi_{V}-238507.31 \varphi_{V}^{2}
$$

with $R^{2}=0.9957$. Fitting of second degree polynomial were performed in OriginPro 9.1 software.

In Table 4 it was also presented ratio between electrical conductivity of nanofluid and electrical conductivity of base fluids, called as enhancement of electrical conductivity. Graphical representation of these data was presented in Fig. 9 (B) and (D). As can be seen, nanofluids S2 have much higher enhancement of electrical conductivity in whole investigated range of volume fraction of nanoparticles in ethylene glycol than S1 nanofluids. The maximum enhancement of electrical conductivity was obtained in the highest tested volume fraction (0.023) for both types of nanofluids and it was over $2000 \%$ and $19073 \%$ respectively for S1 and S2 samples. Such a large increase in electrical conductivity of nanofluids, or even higher, was also reported by few researchers $[54,67,68]$.

\section{Conclusions}

The paper report results of comprehensive experimental measurement of thermal and electrical conductivities and rheological properties as well on this ethylene glycol based graphite/diamonds nanofluids. In addition, in spite of previous reports on diamond nanofluids, this work is the first and unique where influence of nanoparticle and ash content is considered simultaneously, to the best of our knowledge

It was shown that nanofluids mainly behave as yield stress fluids with viscoelastic structure. This behavior is mainly related to nanoparticle volume and ash content. G' and G', yield stress, apparent viscosity of nanofluids are increased with volume content. This trend is also enhanced with higher content in ash within the nanofluids.

Then, the thermal conductivity of nanofluids was shown to be linearly increased with nanoparticle volume content without any influence of ash content, indicating that this enhancement was mainly governed by graphite/diamond phase. However, the maximum enhancement is rather weak and attains $5.8 \%$ at 0.023 volume fraction of particles. Finally, it was demonstrated
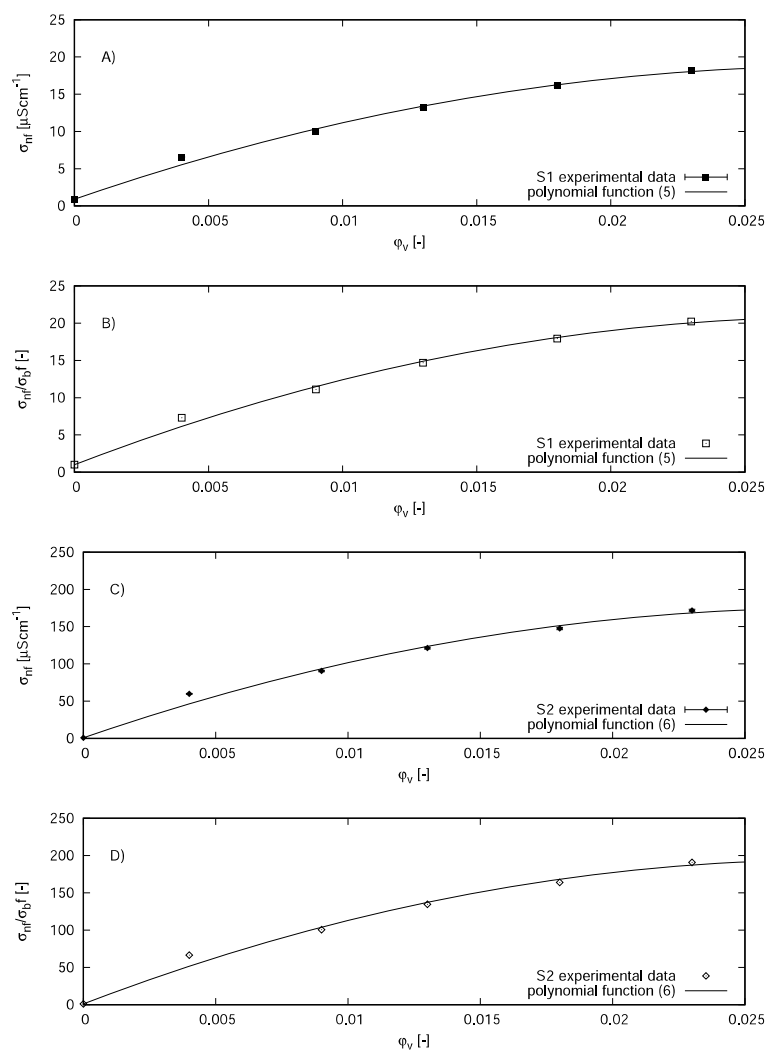

Figure 9: Dependence of electrical conductivity of A) S1 and C) S2, and electrical conductivity enhancement for B) S1 and D) S2 nanofluids on volume fraction of particles at $298.15 \mathrm{~K}$.

that electrical conductivity of nanofluids strongly increased with nanoparticle volume content and can achieve high value at maximum volume content.

\section{Acknowledgments}

Authors wish to thank dr Magdalena Gizowska from Department of Nanotechnology, Institute of Ceramics and Building Materials, Warsaw, Poland for measurements of density of nanopowders. The authors acknowledge also Loïc Joanny from CMEBA, Université Rennes 1 and Mathieu Pasturel from the Institut des Sciences Chimiques de Rennes, Université Rennes 1 for performing respectively SEM and XRD characterization. Research was partially supported by EU COST Action CA15119: Overcoming Barriers to Nanofluids Market Uptake.

\section{References}

[1] X.-Q. Wang, A. S. Mujumdar, Heat transfer characteristics of nanofluids: a review, International journal of thermal sciences 
46 (1) (2007) 1-19.

[2] S. Kakac, A. Pramuanjaroenkij, Review of convective heat transfer enhancement with nanofluids, International Journal of Heat and Mass Transfer 52 (13) (2009) 3187-3196.

[3] S. K. Das, S. U. Choi, H. E. Patel, Heat transfer in nanofluids-a review, Heat transfer engineering 27 (10) (2006) 3-19.

[4] S. Özerinç, S. Kakaç, A. G. Yazıcıoğlu, Enhanced thermal conductivity of nanofluids: a state-of-the-art review, Microfluidics and Nanofluidics 8 (2) (2010) 145-170.

[5] H. Younes, G. Christensen, D. Li, H. Hong, A. A. Ghaferi, Thermal conductivity of nanofluids: a review, Journal of Nanofluids 4 (2) (2015) 107-132.

[6] H. H Al-Kayiem, S. Chun Lin, A. Lukmon, Review on nanomaterials for thermal energy storage technologies, Nanoscience and Nanotechnology-Asia 3 (1) (2013) 60-71.

[7] R. Taylor, S. Coulombe, T. Otanicar, P. Phelan, A. Gunawan, W. Lv, G. Rosengarten, R. Prasher, H. Tyagi, Small particles, big impacts: A review of the diverse applications of nanofluids, Journal of Applied Physics 113 (1) (2013) 011301.

[8] R. Saidur, K. Leong, H. Mohammad, A review on applications and challenges of nanofluids, Renewable and Sustainable Energy Reviews 15 (3) (2011) 1646 - 1668.

[9] D. P. Kulkarni, D. K. Das, R. S. Vajjha, Application of nanofluids in heating buildings and reducing pollution, Applied Energy 86 (12) (2009) 2566-2573.

[10] I. Shahrul, I. Mahbubul, S. Khaleduzzaman, R. Saidur, M. Sabri, A comparative review on the specific heat of nanofluids for energy perspective, Renewable and Sustainable Energy Reviews 38 (2014) 88-98.

[11] A. N. Al-Shamani, M. H. Yazdi, M. Alghoul, A. M. Abed, M. H. Ruslan, S. Mat, K. Sopian, Nanofluids for improved efficiency in cooling solar collectors-a review, Renewable and Sustainable Energy Reviews 38 (2014) 348-367.

[12] O. Mahian, A. Kianifar, S. A. Kalogirou, I. Pop, S. Wongwises, A review of the applications of nanofluids in solar energy, International Journal of Heat and Mass Transfer 57 (2) (2013) 582 594.

[13] S. Senthilraja, M. Karthikeyan, R. Gangadevi, Nanofluid applications in future automobiles: comprehensive review of existing data, Nano-Micro Letters 2 (4) (2010) 306-310.

[14] P. Ghosh, G. Han, M. De, C. K. Kim, V. M. Rotello, Gold nanoparticles in delivery applications, Advanced drug delivery reviews 60 (11) (2008) 1307-1315.

[15] D. Pissuwan, T. Niidome, M. B. Cortie, The forthcoming applications of gold nanoparticles in drug and gene delivery systems, Journal of controlled release 149 (1) (2011) 65-71.

[16] S. Rana, A. Bajaj, R. Mout, V. M. Rotello, Monolayer coated gold nanoparticles for delivery applications, Advanced drug delivery reviews 64 (2) (2012) 200-216.

[17] I. Mahbubul, R. Saidur, M. Amalina, Latest developments on the viscosity of nanofluids, International Journal of Heat and Mass Transfer 55 (4) (2012) 874-885

[18] L. S. Sundar, K. Sharma, M. Naik, M. K. Singh, Empirical and theoretical correlations on viscosity of nanofluids: a review, Renewable and sustainable energy reviews 25 (2013) 670-686.

[19] P. C. Mishra, S. Mukherjee, S. K. Nayak, A. Panda, A brief review on viscosity of nanofluids, International nano letters 4 (4) (2014) 109-120.

[20] S. Chandrasekaran, H. Sivasankaran, D. M. Lal, Effective thermal conductivity and rheological characteristics of ethylene glycol based nanofluids with single-walled carbon nanohorn inclusions, Fullerenes, Nanotubes and Carbon Nanostructures in pres, doi: 10.1080/1536383X.2016.1261285 (0) (2016) 0-0. doi:10.1080/1536383X.2016.1261285.

[21] M. Pastoriza-Gallego, L. Lugo, J. Legido, M. Piñeiro, Thermal conductivity and viscosity measurements of ethylene glycolbased al2o3 nanofluids, Nanoscale Research Letters 6 (1) (2011) 221

[22] J. Albadr, S. Tayal, M. Alasadi, Heat transfer through heat exchanger using al2o3 nanofluid at different concentrations, Case Studies in Thermal Engineering 1 (1) (2013) $38-44$.

[23] Z. Said, M. Sajid, M. Alim, R. Saidur, N. Rahim, Experimental investigation of the thermophysical properties of al2o3nanofluid and its effect on a flat plate solar collector, International Communications in Heat and Mass Transfer 48 (0) (2013) $99-107$.

[24] M. Ghanbarpour, E. B. Haghigi, R. Khodabandeh, Thermal properties and rheological behavior of water based al2o3 nanofluid as a heat transfer fluid, Experimental Thermal and Fluid Science 53 (0) (2014) 227 - 235.

[25] A. Mariano, M. J. Pastoriza-Gallego, L. Lugo, L. Mussari, M. M. Pineiro, Co3o4 ethylene glycol-based nanofluids: Thermal conductivity, viscosity and high pressure density, International Journal of Heat and Mass Transfer 85 (2015) $54-60$.

[26] Z. Said, R. Saidur, A. Hepbasli, N. Rahim, New thermophysical properties of water based tio2 nanofluid - the hysteresis phenomenon revisited, International Communications in Heat and Mass Transfer (0) (2014) in press, doi 10.1016/j.icheatmasstransfer.2014.08.034

[27] L. M. Moreira, E. Carvalho, M. Bell, V. Anjos, A. SantAna, A. P. P. Alves, B. Fragneaud, L. Sena, B. Archanjo, C. Achete, Thermo-optical properties of silver and gold nanofluids, Journal of thermal analysis and calorimetry 114 (2) (2013) 557-564.

[28] N. Shalkevich, W. Escher, T. Burgi, B. Michel, L. Si-Ahmed, D. Poulikakos, On the thermal conductivity of gold nanoparticle colloids, Langmuir 26 (2) (2009) 663-670.

[29] S.-W. Kang, W.-C. Wei, S.-H. Tsai, S.-Y. Yang, Experimental investigation of silver nano-fluid on heat pipe thermal performance, Applied Thermal Engineering 26 (17) (2006) 23772382.

[30] M. Wozniak, P. Rutkowski, D. Kata, Rheological properties and thermal conductivity of aln-poly (propylene glycol) suspensions, Heat and Mass Transfer (2015) 1-10.

[31] M. Wozniak, A. Danelska, P. Rutkowski, D. Kata, Thermal conductivity of highly loaded aluminium nitride-poly(propylene glycol) dispersions, International Journal of Heat and Mass Transfer 65 (2013) $592-598$

[32] G. Żyła, J. Fal, Experimental studies on viscosity, thermal and electrical conductivity of aluminum nitride-ethylene glycol (aln-eg) nanofluids, Thermochimica Acta 637 (2016) 11-16.

[33] G. Żyła, J. Fal, J. Traciak, M. Gizowska, K. Perkowski, Huge thermal conductivity enhancement in boron nitride - ethylene glycol nanofluids, Materials Chemistry and Physics 180 (2016) $250-255$

[34] X. Li, C. Zou, W. Chen, X. Lei, Experimental investigation of $\beta$-cyclodextrin modified carbon nanotubes nanofluids for solar energy systems: Stability, optical properties and thermal conductivity, Solar Energy Materials and Solar Cells 157 (2016) 572-579.

[35] P. Estellé, S. Halelfadl, T. Maré, Thermal conductivity of cnt water based nanofluids: Experimental trends and models overview, Journal of Thermal Enginnering 1 (2) (2015) 381-390.

[36] T. Maré, S. Halelfadl, S. Van Vaerenbergh, P. Estellé, Unexpected sharp peak in thermal conductivity of carbon nanotubes water-based nanofluids, International communications in heat and mass transfer 66 (2015) 80-83.

[37] S. S. Gupta, V. M. Siva, S. Krishnan, T. Sreeprasad, P. K. Singh, T. Pradeep, S. K. Das, Thermal conductivity enhancement of nanofluids containing graphene nanosheets, Journal of Applied Physics 110 (8) (2011) 084302. 
[38] S. S. Park, N. J. Kim, Influence of the oxidation treatment and the average particle diameter of graphene for thermal conductivity enhancement, Journal of Industrial and Engineering Chemistry 20 (4) (2014) 1911-1915.

[39] W. Yu, H. Xie, X. Wang, X. Wang, Significant thermal conductivity enhancement for nanofluids containing graphene nanosheets, Physics Letters A 375 (10) (2011) 1323-1328.

[40] W. Yu, H. Xie, W. Chen, Experimental investigation on thermal conductivity of nanofluids containing graphene oxide nanosheets, Journal of Applied Physics 107 (9) (2010) 094317.

[41] H. Navas, P. Estellé, D. Begin, J. Gleize, J. Ghanbaja, A. Desforges, B. Vigolo, Graphene-based nanofluids for heat transfer applications, in: FEMS Junior Euromat 2016, 2016.

[42] J. Sarkar, P. Ghosh, A. Adil, A review on hybrid nanofluids: recent research, development and applications, Renewable and Sustainable Energy Reviews 43 (2015) 164-177.

[43] M. Afrand, K. N. Najafabadi, M. Akbari, Effects of temperature and solid volume fraction on viscosity of sio 2-mwcnts/sae40 hybrid nanofluid as a coolant and lubricant in heat engines, Applied Thermal Engineering 102 (2016) 45-54.

[44] M. H. Esfe, S. Saedodin, W.-M. Yan, M. Afrand, N. Sina, Study on thermal conductivity of water-based nanofluids with hybrid suspensions of cnts/al2o3 nanoparticles, Journal of Thermal Analysis and Calorimetry 124 (1) (2016) 455-460.

[45] A. A. Minea, Hybrid nanofluids based on al 2 o 3, tio 2 and sio 2: Numerical evaluation of different approaches, International Journal of Heat and Mass Transfer 104 (2017) 852-860.

[46] A. A. Minea, Challenges in hybrid nanofluids behavior in turbulent flow: Recent research and numerical comparison, Renewable and Sustainable Energy Reviews (2016) in press, DOI: 10.1016/j.rser.2016.12.072

[47] B. T. Branson, P. S. Beauchamp, J. C. Beam, C. M. Lukehart, J. L. Davidson, Nanodiamond nanofluids for enhanced thermal conductivity, Acs Nano 7 (4) (2013) 3183-3189.

[48] L. S. Sundar, M. J. Hortiguela, M. K. Singh, A. C. Sousa, Thermal conductivity and viscosity of water based nanodiamond (nd) nanofluids: An experimental study, International Communications in Heat and Mass Transfer.

[49] M. Yeganeh, N. Shahtahmasebi, A. Kompany, E. Goharshadi, A. Youssefi, L. Šiller, Volume fraction and temperature variations of the effective thermal conductivity of nanodiamond fluids in deionized water, International Journal of Heat and Mass Transfer 53 (15) (2010) 3186-3192.

[50] W. Yu, H. Xie, Y. Li, L. Chen, Q. Wang, Experimental investigation on the thermal transport properties of ethylene glycol based nanofluids containing low volume concentration diamond nanoparticles, Colloids and Surfaces A: Physicochemical and Engineering Aspects 380 (1) (2011) 1-5.

[51] T. Tyler, O. Shenderova, G. Cunningham, J. Walsh, J. Drobnik, G. McGuire, Thermal transport properties of diamond-based nanofluids and nanocomposites, Diamond and related materials 15 (11) (2006) 2078-2081.

[52] L. S. Sundar, K. Shusmitha, M. K. Singh, A. C. Sousa, Electrical conductivity enhancement of nanodiamond-nickel (nd-ni) nanocomposite based magnetic nanofluids, International Communications in Heat and Mass Transfer 57 (2014) 1-7.

[53] G. Shukla, H. Aiyer, Thermal conductivity enhancement of transformer oil using functionalized nanodiamonds, IEEE Transactions on Dielectrics and Electrical Insulation 22 (4) (2015) 2185-2190

[54] D. H. Fontes, G. Ribatski, E. P. Bandarra Filho, Experimental evaluation of thermal conductivity, viscosity and breakdown voltage ac of nanofluids of carbon nanotubes and diamond in transformer oil, Diamond and Related Materials 58 (2015) 115121.
[55] C. Wilson, H. Ma, K. Park, High thermal conductivity of diamond nanofluids and its effect on the heat transport capability in an oscillating heat pipe, in: ASME 2006 International Mechanical Engineering Congress and Exposition, American Society of Mechanical Engineers, 2006, pp. 289-295.

[56] H. Liu, M. Bai, Y. Qu, The impact of oil-based diamond nanofluids on diesel engine performance, in: Proceedings of the FISITA 2012 World Automotive Congress, Springer, 2013, pp. 13131319.

[57] J. J. Taha-Tijerina, T. N. Narayanan, C. S. Tiwary, K. Lozano, M. Chipara, P. M. Ajayan, Nanodiamond-based thermal fluids, ACS applied materials and interfaces 6 (7) (2014) 4778-4785.

[58] S. Torii, Experimental study on convective heat transfer of aqueous suspensions of nano-diamond particles, in: Proceedings of International Symposium on EcoTopia Science, 2007, pp. 352357.

[59] P.-H. Lee, T. S. Nam, C. Li, S. W. Lee, Environmentallyfriendly nano-fluid minimum quantity lubrication (mql) mesoscale grinding process using nano-diamond particles, in: Manufacturing Automation (ICMA), 2010 International Conference on, IEEE, 2010, pp. 44-49.

[60] J. S. Nam, P.-H. Lee, S. W. Lee, Experimental characterization of micro-drilling process using nanofluid minimum quantity lubrication, International Journal of Machine Tools and Manufacture 51 (7) (2011) 649-652.

[61] M. Ghazvini, M. Akhavan-Behabadi, E. Rasouli, M. Raisee, Heat transfer properties of nanodiamond-engine oil nanofluid in laminar flow, Heat Transfer Engineering 33 (6) (2012) 525532.

[62] L. S. Sundar, M. K. Singh, E. V. Ramana, B. Singh, J. Grácio, A. C. Sousa, Enhanced thermal conductivity and viscosity of nanodiamond-nickel nanocomposite nanofluids, Scientific reports 4 .

[63] C. Novak, D. Kingman, K. Stern, Q. Zou, L. Gara, Tribological properties of paraffinic oil with nanodiamond particles, Tribology Transactions 57 (5) (2014) 831-837.

[64] L. S. Sundar, M. K. Singh, A. C. Sousa, Experimental thermal conductivity and viscosity of nanodiamond-based propylene glycol and water mixtures, Diamond and Related Materials 69 (2016) 49-60.

[65] C. Yang, P. Ma, F. Jing, D. Tang, Excess molar volumes, viscosities, and heat capacities for the mixtures of ethylene glycol+ water from $273.15 \mathrm{k}$ to $353.15 \mathrm{k}$, Journal of Chemical and Engineering Data 48 (4) (2003) 836-840

[66] G. Żyła, Thermophysical properties of ethylene glycol based yttrium aluminum garnet (y3al5o12-eg) nanofluids, International Journal of Heat and Mass Transfer 92 (2016) $751-756$.

[67] M. Dong, L. Shen, H. Wang, H. Wang, J. Miao, Investigation on the electrical conductivity of transformer oil-based aln nanofluid, Journal of Nanomaterials 2013 (2013) 164.

[68] S. Sikdar, S. Basu, S. Ganguly, Investigation of electrical conductivity of titanium dioxide nanofluids, International Journal of Nanoparticles 4 (4) (2011) 336-349. 
Graphical abstract

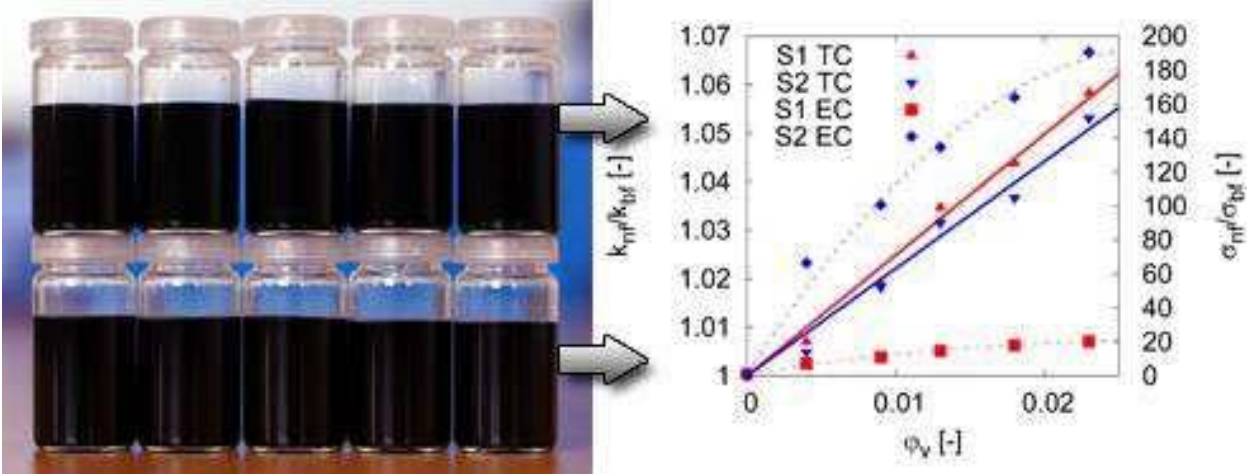




\section{Highlights}

- Thermophysical properties of ethylene glycol based graphite/diamonds mixture nanofluids were investigated

- Ash content changes significantly rheological properties of nanofluids containing graphite/nanodiamonds mixture nanoparticles

- Ash content does not affect thermal conductivity, but has a big impact on electrical conductivity of nanofluids 